\title{
The Fate of Disi Aquifer as Stratigic Groundwater Reserve for Shared Countries (Jordan and Saudi Arabia)
}

\author{
Alsharifa Hind Jasem ${ }^{1}$, Maisa'a Shammout ${ }^{1}$, Dheaya AlRousan ${ }^{2}$, Marwan AlRaggad ${ }^{1}$ \\ ${ }^{1}$ Water, Energy and Environment Research Center (WEE), Jordan University, Amman, Jordan \\ ${ }^{2}$ Land Water and Environment Department, Hashimiate University, Zerqa, Jordan \\ E-mail: hind_geology@yahoo.com \\ Received June 13, 2011; revised August 25, 2011; accepted September 26, 2011
}

\begin{abstract}
Disi is a fossil groundwater shred between Jordan and Saudi Arabia with a very high quality properties, this water is limited and has been used for irrigation purposes between both countries, this study helps in highlighted the importance of this water as stratigic reserve to be use later on. This study shows that the amounts of groundwater affected by the thickness of the saturated zone in the aquifer, the porosity of the aquifer and the groundwater flow in the basin. Abstraction from the aquifer will affect water quality so this point must be clearly understood all the time.
\end{abstract}

Keywords: Aquifer, Groundwater, Fossile Aquifer, Safe Yeild, Transboundary Aquifer, Rock Retention, Groundwater Flow, Saturated Zone

\section{Introduction}

Disi is a fossil water aquifer extending from the southern edge of the Dead Sea in Jordan to Tabuk in northwest Saudi Arabia. Significant exploitation of the Jordanian side of the aquifer started in 1980. At present Aqaba city is provided with 16.5 MCM for domestic purposes and 75 MCM for agricultural purposes. Saudi Arabia extracts around 4 BCM yearly and uses it for irrigation purposes [1].

Increasing population, improving life standards and development of the country lead to increase utilization of water resources in Jordan, Table 1, limited and shortage of surface water resources force the government to over exploitation of main groundwater resources, many aquifers are overexploited now, other are with low water quality, Disi aquifer in the south is one of the highest water quality in Jordan, but it is a fossile aquifer which means that the water is from very long time came during past geologic periods and the extracted water will not be recharged again [2].

Increased utilization of groundwater resources from Disi aquifer in Jordan cannot be contemplated without addressing regional groundwater issue.

There have been several water resource management measures adopted in Jordan including the Water Utility Policy (1997), the Groundwater Management Policy (1998), the Irrigation Water Policy (1998) and the Wastewater Management Policy (1998), [3].

For a number of years supply has been outstripped by demand in the Greater Amman Area and the Water Authority of Jordan has had no option but to implement a water rationing program during the summer months to deal with the water shortage. The situation has been on-going since 1988 and continues to deteriorate each year as demand increases which has led to a rationing program for the entire year with very low reliability during the summer period [3].

The scarcity of water in Jordan makes the management of this critical resource very complex from a political, technical, socio-economic and environmental perspective. The water budget of Jordan is around 1 billion cubic meters per annum, which is considered relatively low then compared to the social, economic, and environmental needs of the country. In any water strategy the following stakeholders: domestic, industrial, touristic, and agricultural sectors should be considered [4].

The main goal of the study is to estimate the amounts of water in the Disi transboundary aquifer that is avail- 
able for pumbing and then to estimate the safe yield of the water amount that will be used and extracted from this aquifer.

\section{Methodology}

Collecting data about water depths in the aquifer, aquifer bottoms in different places and then mapping these data using GIS system environment to estimate the saturated zone in the study area, [5].

Then by calculating different hydrological properties of the aquifer the amount of water that is held in the pores and then estimation of the water amounts that are available to be used.

\section{Discussion}

Disi is a fossil water aquifer extending from the southern edge of the Dead Sea in Jordan to Tabuk in northwest Saudi Arabia. Significant exploitation of the Jordanian side of the aquifer started in 1980. At present Aqaba city is provided with 16.5 MCM for domestic purposes and 75 MCM for agricultural purposes, [6,7].

The depth to water table in that aquifer ranging from $100 \mathrm{~m}$ upto $1300 \mathrm{~m}$, Figure 1 shows the distribution of water depths in the study area.

The bottom of the aquifer lies on the depth which ranging from $200 \mathrm{~m}$ upto $1400 \mathrm{~m}$ as shown in Figure 2.

Thickness of saturated zone is the distance between the bottom of the aquifer and the top of water level, in the study area this is shown in Figure 3, which ranges from $10 \mathrm{~m}$ upto about 1100 .

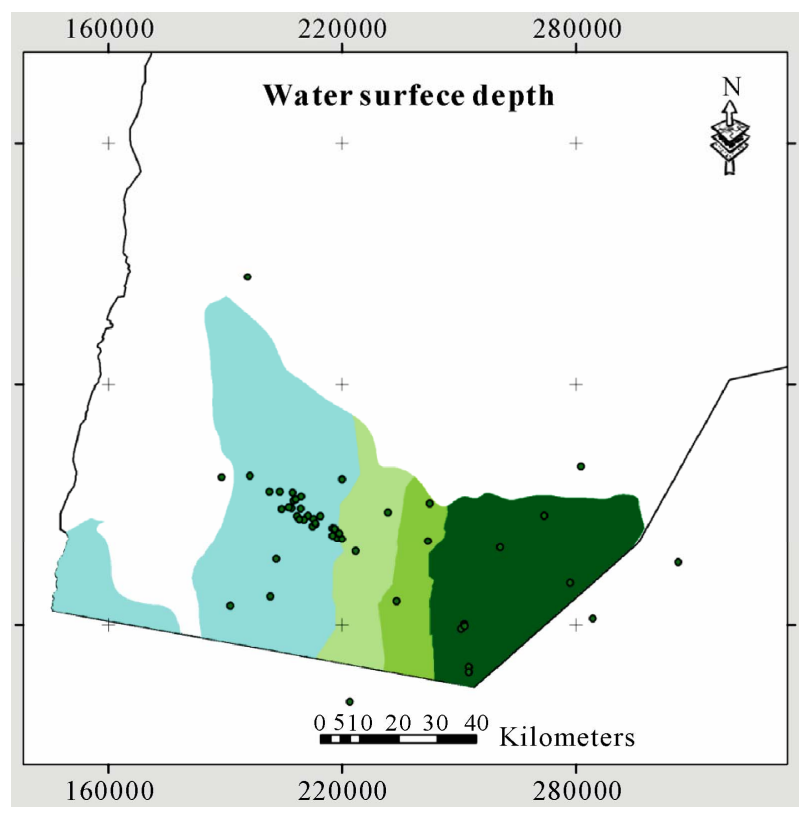

Figure 1. Depth to water table in Disi aquifer.

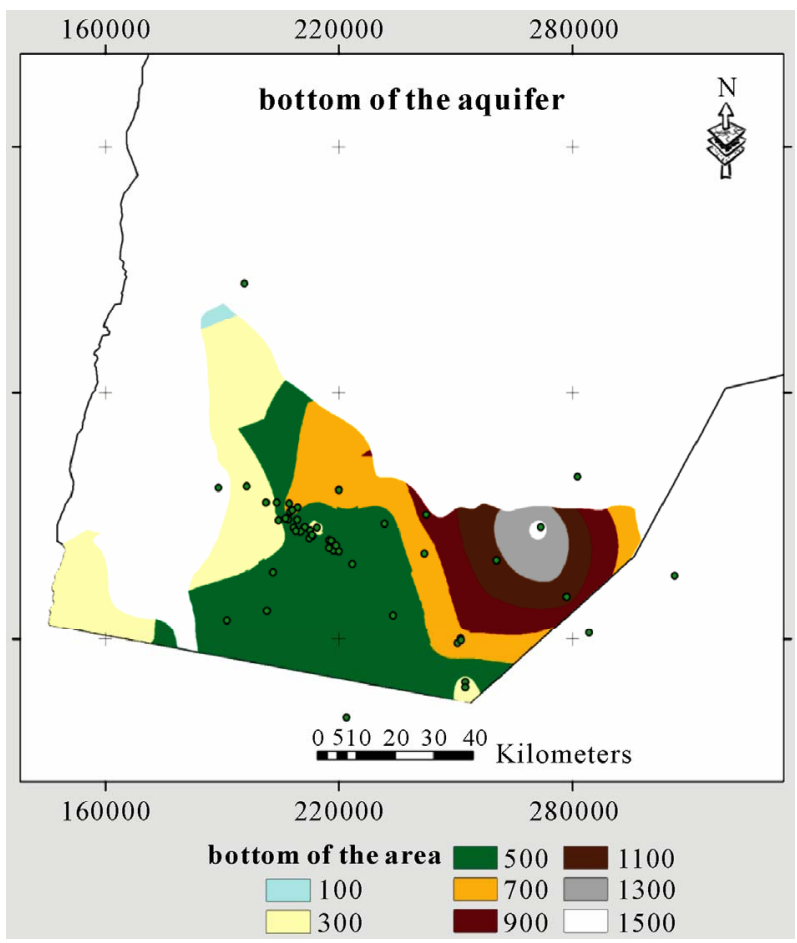

Figure 2. Bottom of Disi aquifer.

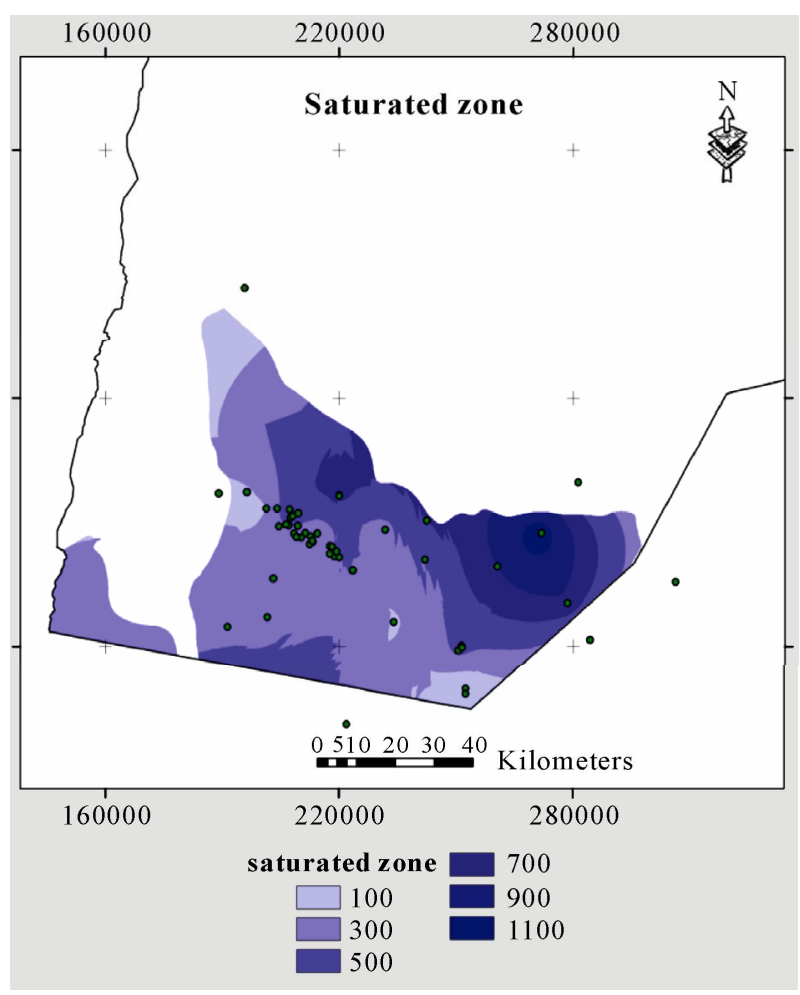

Figure 3. Saturated zone in the Disi.

Because of this deep sandstone aquifer, then the porosity of the rock is less than the normal porosity of sandstone, in addition to the presence of fine cement 
materials between the porous sandstone, this make the porosity of the saturated zone around $12 \%$, accordingly the estimated water volumes in the aquifer shown in Figure 4.

Because of the rock retention and the water that wont be able to be pumbed from the bores of the sandstone the avilable amounts of water expected to be around $60 \%$ of the available water in the rock, so the water volumes that could be pumbed from the aquifer (also these amounts may deteriorate the water qualituy) so the water amounts that are available in the aquifer are shown in Figure 5.

Table 1. Future water demand, supply and deficit in Jordan (Million Cubic Meters/year).

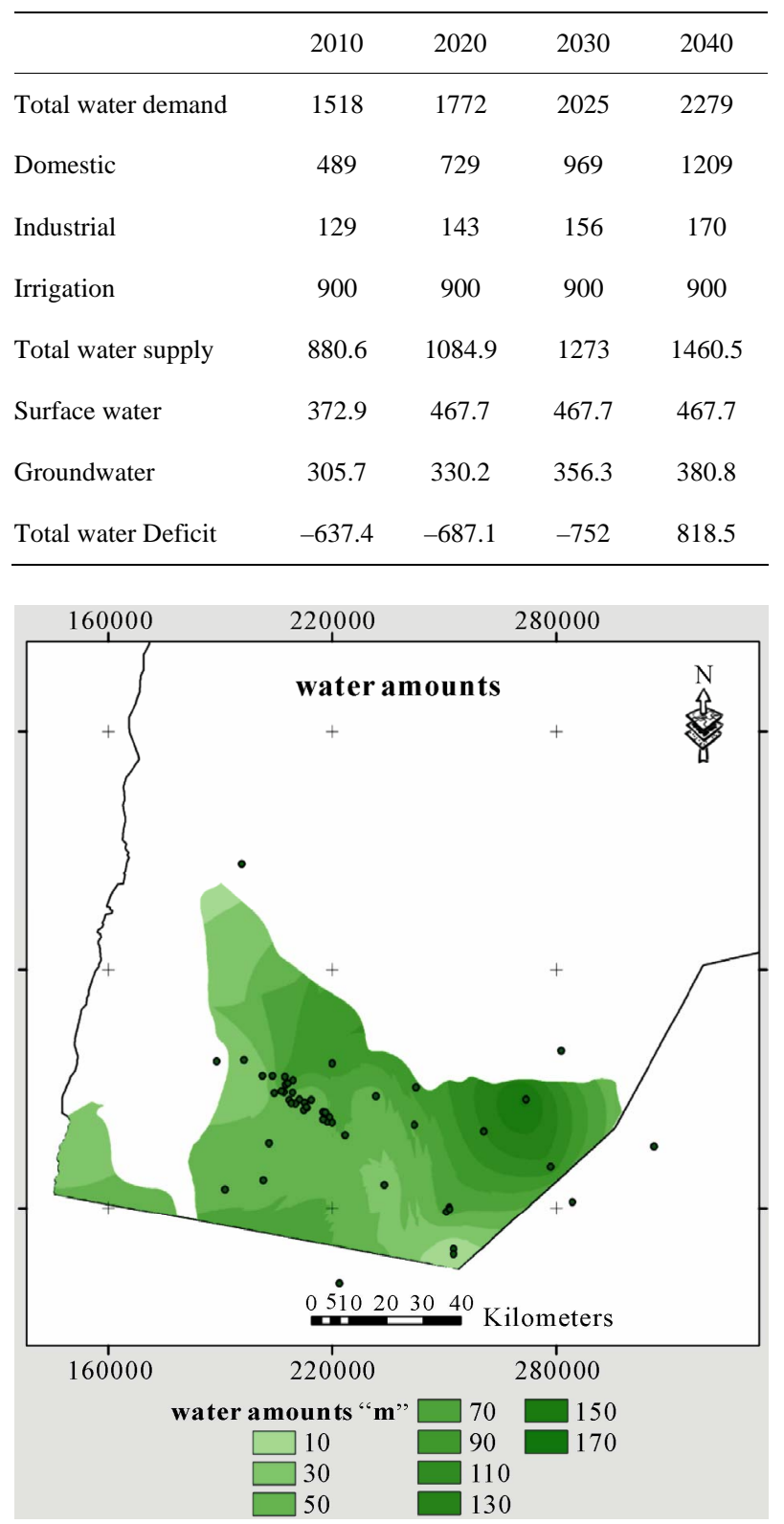

Figure 4. Water amounts in the saturated zone.
Table 2. Amounts of water in the aquifer.

\begin{tabular}{|c|c|c|}
\hline Water content & Polygon area & BCM \\
\hline 10 & 301458562.6 & 3.0146 \\
\hline 70 & 4421690.8 & 0.3095 \\
\hline 50 & 1711.7 & 0.0001 \\
\hline 10 & 12290.9 & 0.0001 \\
\hline 30 & 134114.1 & 0.0040 \\
\hline 70 & 24425.9 & 0.0017 \\
\hline 70 & 3413.6 & 0.0002 \\
\hline 30 & 9394.0 & 0.0003 \\
\hline 50 & 58807.8 & 0.0029 \\
\hline 70 & 115624.6 & 0.0081 \\
\hline 10 & 131869746.8 & 1.3187 \\
\hline 50 & 4178.8 & 0.0002 \\
\hline 50 & 11834.3 & 0.0006 \\
\hline 30 & 59989.6 & 0.0018 \\
\hline 50 & 6359734.9 & 0.3180 \\
\hline 10 & 40374.4 & 0.0004 \\
\hline 10 & 1711.7 & 0.0000 \\
\hline 30 & 43765.1 & 0.0013 \\
\hline 50 & 151413.6 & 0.0076 \\
\hline 10 & 66025674.6 & 0.6603 \\
\hline 90 & 197308391.8 & 17.7578 \\
\hline 30 & 78399353.5 & 2.3520 \\
\hline 30 & 2500.0 & 0.0001 \\
\hline 10 & 8438.7 & 0.0001 \\
\hline 10 & 6716.9 & 0.0001 \\
\hline 30 & 69739.6 & 0.0021 \\
\hline 50 & 192574.5 & 0.0096 \\
\hline 70 & 461603750.8 & 32.3123 \\
\hline 30 & 2500.0 & 0.0001 \\
\hline 30 & 229442.9 & 0.0069 \\
\hline 50 & 1282160381.2 & 64.1080 \\
\hline 10 & 41735664.9 & 0.4174 \\
\hline 50 & 19563686.8 & 0.9782 \\
\hline 30 & 3142665457.7 & 94.2800 \\
\hline 10 & 169658360.7 & 1.6966 \\
\hline
\end{tabular}




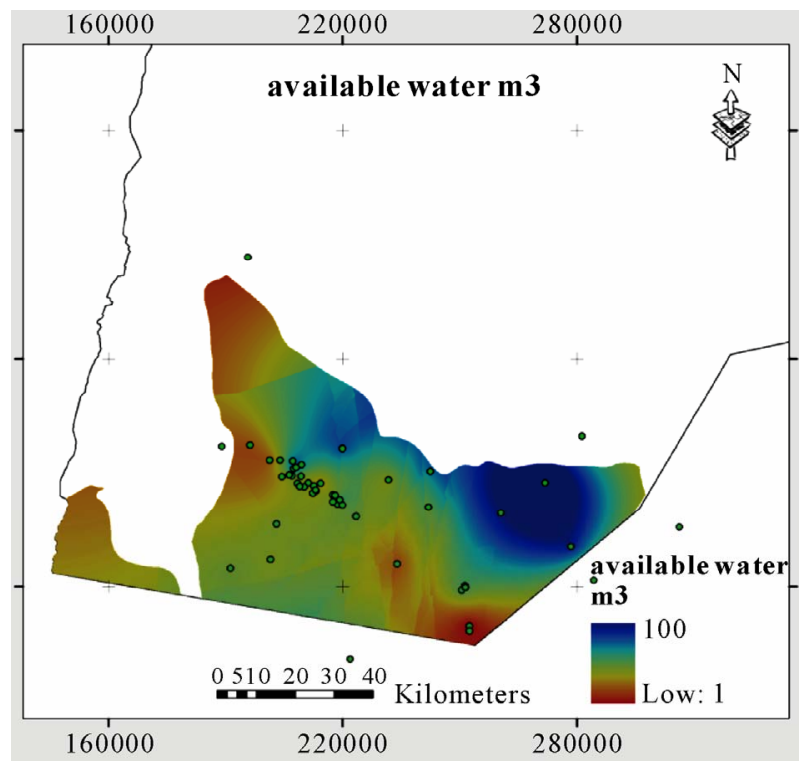

Figure 5. Available water in the Disi aquifer.

\section{Results}

Classifying the amounts of water all around the study area and calculating the areas of each polygon that contains data about water amount gave clear data aboul water volumes that are available to the water abstraction in the study area, Table 2 shows summary for these data and the expected water amounts that are exist in the studied aquifer, according to this table these amounts are around 2.2 BCM.

Because of the low permeability and the negligible recharge amounts this does not include the effect of the water flow that come from Saudi Arabia.

\section{Recommendations}

Possible ways to protect Disi:

Form a joint Saudi Jordanian committee to work on preserving the Disi aquifer from getting exploited. This committee should work on:

- reduction of the amounts of water that are extracted from the aquifer,
- Consider sea water desalination both on the Jordanian and Saudi part

- Stop all the agricultural activities that are taken place in the area and keep the water that is extracted for higher water uses.

- Finally to manage different agricultural patterns those are used now and find ways to effective agricultural patterns [8].

\section{References}

[1] BGR and WAJ, "Groundwater Resources of Jordan, Vol. 3-Structural Features of the Main Hydro-geological Units in Northern Jordan, Water Authority of Jordan (WAJ) and Federal Institute for Geosciences and Natural Resources (BGR),” BGR-Archive, Vol. 57, No. 118702, 1994, p. 30.

[2] E. Salameh, "Over-Exploitation of Groundwater Resources and Their Environmental and Socio-Economic Implications: The Case of Jordan,” Water International, Vol. 33, No. 1, 2008, pp. 55-68. doi:10.1080/02508060801927663

[3] MOI-Ministry of Water and Irrigation, Open Files, Jordan, 2009.

[4] GTZ and NRA, "National Water Master Plan of Jordan. Agrarund Hydrtechnik GMBH ESSE,” Bundersanstalt fur Geowissenschaeien und Rohstoffe, Hannover, 1977.

[5] ESRI-Environmental Systems Research Institute, ArcView GIS version 9.1. A Computer Software to Visualize, Explore, Query and Analyze Data Spatially, USA, 2006.

[6] C. Drake, "Water Resource Conflicts in the Middle East," Journal of Geography, Vol. 96, No. 1, January-February 1997, pp. 4-12.

[7] Ministry of Water and Irrigation, "National Water Master Plan.” Amman: Ministry of Water and Irrigation, The Hashemite King of Jordan. http://www.mwi.gov.jo/NWMP

[8] R. Krishna and S. M. A. Salman, "International Groundwater Law and the World Bank Policy for Projects on Tranboundary Groundwater,” In: Groundwater: Legal and Policy Perspectives: Proceedings of a World Bank Seminar, 1999. 